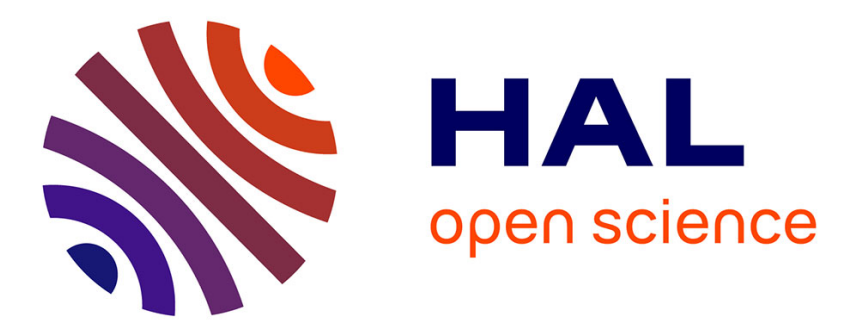

\title{
Extreme Life-Cycle and Sex Ratio Variation among Sexually Produced Clones of the Aphid Rhopalosiphum padi (Homoptera: Aphididae)
}

Claude Rispe, Joël Bonhomme, Jean-Christophe Simon

\section{To cite this version:}

Claude Rispe, Joël Bonhomme, Jean-Christophe Simon. Extreme Life-Cycle and Sex Ratio Variation among Sexually Produced Clones of the Aphid Rhopalosiphum padi (Homoptera: Aphididae). Oikos, 1999, 86 (2), pp.254-264. 10.2307/3546443 . hal-02699278

\section{HAL Id: hal-02699278 \\ https://hal.inrae.fr/hal-02699278}

Submitted on 1 Jun 2020

HAL is a multi-disciplinary open access archive for the deposit and dissemination of scientific research documents, whether they are published or not. The documents may come from teaching and research institutions in France or abroad, or from public or private research centers.
L'archive ouverte pluridisciplinaire HAL, est destinée au dépôt et à la diffusion de documents scientifiques de niveau recherche, publiés ou non, émanant des établissements d'enseignement et de recherche français ou étrangers, des laboratoires publics ou privés. 


\title{
Extreme life-cycle and sex ratio variation among sexually produced clones of the aphid Rhopalosiphum padi (Homoptera: Aphididae)
}

Claude Rispe, Joël Bonhomme and Jean-Christophe Simon

\begin{abstract}
Rispe, C., Bonhomme, J. and Simon, J.-C. 1999. Extreme life-cycle and sex ratio variation among sexually produced clones of the aphid Rhopalosiphum padi (Homoptera: Aphididae). - Oikos 86: 254264
\end{abstract}

\begin{abstract}
The aphid Rhopalosiphum padi exhibits considerable life-cycle variation, showing coexistence betwcen lineages that alternate asexual and sexual reproduction (cyclical parthenogens), lineages that are entircly asexual (obligate parthenogens), and maleproducing obligatc parthenogens. We collected 222 sexually produced clones, in two regions of France, from 1991 to 1994. In experiment 1, with three replicates per clone, we determined the life-cycle of the clones by placing them in conditions inducing the production of gynoparae (the precursors of sexual females) and males. A substantial proportion of the clones consisted of obligate parthenogens. These may result from occasional matings between females (from cyclical parthenogens) and males that are produced by obligate parthenogens that transmit their life-cycle character. Such matings would create bi-directional gene flow between the pools of sexual and asexual lineages and would be likely to modify the relative cost of sex and asex. We studied sex allocation variation in the cyclically parthenogenetic clones, and identified two main phenotypes, one male-biased and one strongly gynopara-biased. In experiment 2, with four of these field-collected clones and twenty replicates per clone, we confirmed that at least some clones are consistently male- or gynopara-biased. In experiment 3, we studied two parental clones $(F$ and $H)$ that were male-biased, and $13 \mathrm{~F} \times \mathrm{F}$ and $14 \mathrm{H} \times \mathrm{H}$ self-crossed offspring clones. Nearly all of these clones were also consistently malc-biased, strongly supporting genetic control of sex allocation trait.
\end{abstract}

C. Rispe, J. Bonhomme and J.-C. Simon, Laboratoire de Zoologie, INRA, Domaine de la Motte-au-Vicomte, F-35653 Le Rheu cedex, France (rispe@rennes.inra-fir).

This paper focusses on three questions: 1) whether asexuals can contribute to the gene pool of sexuals, 2) whether, and to what extent, sex ratio of sexual offspring in aphids is variable, and 3) whether the sex ratio is genetically determined.

The coexistence of sexual and asexual reproductive modes is problematic in light of the "cost of sex" or the cost of male production (Maynard Smith 1971, Williams 1975). Numerous authors have suggested a variety of compensating advantages of sex (for reviews, see Michod and Levin 1988, Stearns 1990 and Hurst and Peck 1996). Cyclically parthenogenetic species (that regularly alternate sexual and clonal genera- tions) provide opportunity to test these theories, since cyclically parthenogenetic lineages often have obligately parthenogenetic counterparts, derived from cyclical populations by the loss of the sexual phase from their life-cycles. Comparative studies of life-cycle variants should help identify the selective forces responsible for the maintenance of sex in such species, but such studies require knowledge about the degree of genetic connection between sexual and asexual lineages. We present experimental results bearing on this question, from a study of regional variability in life-cycle in the aphid species Rhopalosiphum padi $\mathrm{L}$.

Accepted 19 November 1998

Copyright 6 OIKOS 1999

ISSN 0030-1299

Printed in Ircland - all rights reserved 
Cyclical parthenogenesis is the typical life-cycle of aphids, while a small minority of species are entirely asexual (Remaudière 1953, Lampel 1968, Moran 1992). Since sexually produced eggs are the only cold-resistant stage in most aphids, only cyclically parthenogenetic aphids can survive cold winters. However, in several aphid species, obligately parthenogenetic lineages coexist with cyclical parthenogens. The local balance between the two types of life-cycle could be determined by the winter climate, with obligate parthenogens dominating in mild regions, cyclical parthenogens in cold regions, and a mixture in intermediate climates (Rispe et al. 1998b). This hypothesis is supported by studies of several aphid species, in which an inverse correlation between the proportion of cyclical parthenogens and the winter temperature has been established (Blackman 1974, Dean 1974, Dedryver and Gellé, 1982, Tatchell et a1. 1988, Wöhrmann and Tomiuk 1988, Simon et al. 1991). This evidence secms to contradict alternative hypotheses of an advantage of sex through greater genetic diversity, as in models based on the lottery metaphor (increased genetic diversity pays when only one genotype can thrive in a given patch, e.g., Williams and Mitton 1973) or as in models based on host-parasite coevolution (selection against common genotypes mediated by parasites favors sex, e.g., Hamilton 1980).

In conditions that induce the production of males and sexual females in other aphids, obligate parthenogens often may produce males in addition to overwintering parthenogenetic females. In Myzus persicae and $R$. padi, males produced by otherwise obligately parthenogenetic clones are able to mate with sexual females in laboratory experiments. A fraction of the clones resulting from these matings are obligate parthenogens which apparently inherit genes of maleproducing obligate parthenogenesis (Blackman 1972, Simon et al. 1994). Ascertaining the existence of such gene-flow between the pools of sexual and asexual lineages is critical for evaluating the fitness costs and benefits of each type of life-cycle. First, the mating of males produced by obligate parthenogens with sexual females may preserve genes of obligate parthenogenesis during cold winters that would otherwise exterminate genes for parthenogenesis. Sccond, males produced by obligate parthenogens will also contribute to the fitness of obligate parthenogenesis genes by repeatedly producing new asexulal lineages via sexual reproduction. A similar scenario, demonstrated in Daphnia, has been termed a "sex-limited meiosis suppressor mechanism" (Hebert 1981; Innes and Hebert 1988). A consequence of this mechanism is increased genetic variability of asexual lineages (Lynch and Gabricl 1983, Hebert et al. 1989). Extensive surveys on mitochondrial DNA variation in $R$. padi showed that cyclically and obligately parthenogenetic lineages each have a characteristic mtDNA haplotype (I for obligate parthenogens, II or related for cyclical parthenogens), but that a few obli- gately parthenogenetic lineages possessed haplotype II (Martinez-Torres et al. 1996, 1997, Simon et al. 1996a). These patterns have been interpreted as resulting from occasional gene flow between life-cycle variants mediated by males produced by obligate parthenogens. Because gene flow is unidirectional for maternally inherited genomes like mtDNA, this scenario could preserve considerable mtDNA differentiation between life-cycle forms. Our study provides further evidence for such gene llow in $R$. padi.

A critical factor in the balance between sexual and asexual reproduction is the sex ratio, which led us to investigate sex ratio variability in $R$. padi. Sex ratio theory generally predicts that investment in the sexes should be equal at the population level, because frequency-dependent selection favors parents that invest more in the rarer sex (Fisher 1930; Charnov 1982) - the cost of producing $50 \%$ males is in fact the basis of the relative cost of sexual versus asexual reproduction. In aphids, the balance between the sexes at the population level could be influenced by an input of males produced by obligate parthenogens, as might be the casc in regions where cyclical- and male-producing obligatc parthenogens coexist. Also worth examination is individual variability in sex ratio, since the theory does not require that broods from all parents will have balanced investments when population sex ratios are balanced. In fact, polymorphism in individual sex allocation could be favorably selected if biased individual sex ratios diminish the risk of inbreeding (Charnov 1982). Nonetheless, there seem to be few examples of sex ratio polymorphism, probably due to constraints imposed by the chromosomal mechanisms of sex ratio determination $(\mathrm{XX} / \mathrm{XY}, \mathrm{ZW} / \mathrm{ZZ})$ that impose a statistical equality of the sexes among progeny. In organisms (including haplodiploid Hymenoptera and cyclical parthenogens) that have maternal control over the sex ratio, sex allocation polymorphism is more common (Godfray 1990). For example, Innes and Dunbrack (1993) demonstrated the coexistence of clones that produced either entirely sexual female broods or dominantly male broods in Daphnia pulex. Our study of $R$. padi, in which the sex determination is XX (females)/XO (males), provides an additional example of extreme polymorphism in brood sex ratio in a cyclical parthenogen.

\section{Material and methods}

\section{Further relevant details on the life-cycle of $R$. padi}

Rhopalosiphum padi achieves sexual reproduction on a specific winter-host (Prunus padus L. in Europe) while many species of Gramineae may serve as summer-hosts, on which reproduction is parthenogenetic (Dixon and Glen 1971). The production of sexuals is triggered by 
decreasing temperature and day length in the fall (Hille Ris Lambers 1966, Lees 1966). Cyclically parthenogenetic lineages produce gynoparae (parthenogenetic females that give birth exclusively to sexual females) and males on summer-hosts, both of which fly to the winter-host. There, the sexual females larviposited by gynoparae mate with males upon maturation and lay diapausing cold-resistant eggs. The Fisherian prediction of equality of investment in the sexes thus applies to gynoparae and males, not to sexual females (Newton and Dixon 1987). In a population madc of cyclical parthenogens, the investment ratio which is the ratio of gynoparae to males should be balanced, while the ratio between sexual females and males is female-biased (for a life cycle diagram and analytical proof of this verbal argument, see Appendix).

\section{Clone collection}

A total of 222 clones of $R$. padi were collected in two regions in France: in the occanic north-west (at Rennes, where winters are usually mild) in 1991, 1992, 1993 and 1994, and in the continental north-east (at Colmar in 1992 and 1993, and Epinal, $80 \mathrm{~km}$ from Colmar, in 1994) where winter climate is regularly cold (i.e. lethal to overwintering obligate parthenogens). Collections were made in the spring, from March to April, on the winter-host, $P$. padus, on which sexual reproduction occurred in the preceding fall. Each egg is genetically unique, and we collected only fundatrices (the first generation of parthenogenetic females that hatch from the eggs), ensuring that each clone was genetically distinct.

\section{Life-cycle characterization}

After collection, clones were stored and reared under conditions that ensure continuous parthenogenetic reproduction ( $\mathrm{L}: \mathrm{D} 16: 8,20^{\circ} \mathrm{C}$ ). In experiment 1 , four months after collection, they were induced to produce sexuals using standard methods (Simon et al. 1991), by placing aphids in long night (L:D 8:16) and low temperature conditions $\left(12^{\circ} \mathrm{C}\right)$. Three parents were studied for each clone, but due to the mortality of some parents, only a single parent or two parents could be studied in 34 cloncs. When the three repetitions were carried out, responses were always homogeneous (i.e. the same lifecycle was produced), so the whole set of clones was retained for analysis of life-cycle variability. The fecundity, longevity and sex ratio (defined as the proportion of gynoparae in the offspring) of each parent were recorded.

In experiment 2, a subset of four clones was induced, and 20 parents were tested for each clone. These clones were selected on the basis of their responses in experiment 1 , in order to evaluate the degree of intraclonal sex ratio variation and to check for the existence of consistently biased sex ratios in some clones. Goodnessof-fit tests (or $G$-tests) were performed to test the within-clone homogeneity and the significance of the biases in sex ratio.

\section{Analysis of sex ratio inheritance in two self-crosses}

Offspring from two cyclically parthenogenetic clones (F and $\mathrm{H}$ ) were self-crossed. In cxperiment 3 , the clones resulting from self-crossings were induced in turn to produce sexulals, using the method described above. These crosses were made as part of a parallel study of the inheritance of life-cycle differences in $R$. padi. Both $\mathrm{F}$ and $\mathrm{H}$ were male-biased clones, so the analysis of the sex ratio of offspring clones was only a preliminary step in the study of sex ratio inheritance.

\section{Results}

\section{Life-cycle variation of populations sampled on the} winter-host

In experiment 1, we showed that in oceanic conditions, in 1991 and 1994, a fraction of the clones produced by

Table 1. Response of clones of Rhopalosiphum padi to induction of scxuals. All clones were collected as fundatrices, the first parthenogenetic generation that develops from the eggs, on the winter-host Prumus padus. Therefore, each clone was the result of sexual reproduction in the preceding fall and represents a unique genotype. Year and region of collection, the number of clones collected, and the response displayed are indicated.

\begin{tabular}{|c|c|c|c|c|c|}
\hline Year & Region & $N$ & $\begin{array}{l}\text { Cyclical } \\
\text { parthenogens }\end{array}$ & $\begin{array}{l}\text { Male-producing } \\
\text { obligate parthenogens }\end{array}$ & $\begin{array}{l}\text { Non male-producing } \\
\text { obligate parthenogens }\end{array}$ \\
\hline 1991 & Oceanic & 17 & 11 & 1 & 5 \\
\hline 1992 & Continental & 35 & 35 & & \\
\hline \multirow[t]{2}{*}{1993} & Oceanic & 36 & 36 & & \\
\hline & Continental & 27 & 27 & & \\
\hline
\end{tabular}




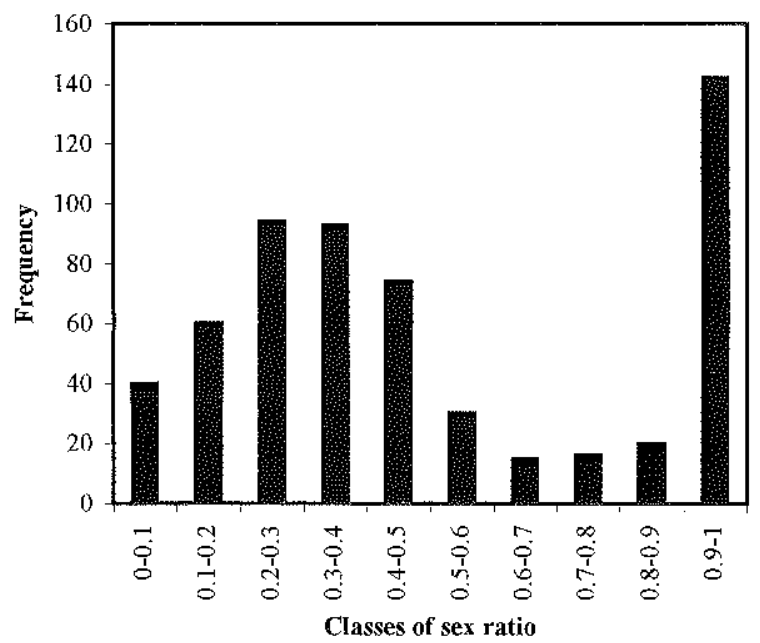

Fig. 1. Distribution of sex ratio (proportion of gynoparae) in the pooled data of all populations of Rhopalosiphum padi (543 replicates from 204 cyclically parthenogenetic clones collected in the field) after induction of scxuals.

sexual reproduction were obligate parthenogens $(35 \%$ and $23 \%$, respectively, Table 1 ). The remaining clones were cyclical parthenogens. While only one obligate parthenogen was male-producing in 1991, the identification of male-producing clones is not simple because low rates of male production may not be detected among the offspring of only three parents (Simon et al. 1991).

\section{Sex ratio variation of cyclically parthenogenetic clones.}

Bimodal distribution of sex ratio phenotypes

The most striking result of the analysis of sex ratio variation was the clearly bimodal distribution of brood sex ratios, with modes at around $30 \%$ and $95 \%$ gynoparae (Fig. 1). Since gynoparae are produced first, individuals with shortened life-span and reduced fecundity might produce accidentally gynopara-biased sex ratios. However this artifactual explanation does not explain the observed sex ratio variation because sex ratios correlated positivcly with individual fecundities $(\rho=0.38)$. Individuals with sex ratios $>90 \%$ produced a mean of 28.8 larvae, significantly more than individuals with lower sex ratios, which produced only 20.6 larvae on average $(t=7.53, P(T<$ $t)<0.0001)$. The lower fecundity of male-producing individuals is consistent with a study of another aphid specics showing that the viability of male embryos is lower than that of female embryos (Crema 1979). However, the longevity of gynopara-biased parents $(60.5 \mathrm{~d})$ and male-biased parents $(64.6 \mathrm{~d})$ is slightly but significantly different $(t=2.8, P(T<t)=$ $0.003)$.
Variation with year and region of sex ratio

Sex ratio bimodality was consistently found at each region (oceanic or continental) and year, while the ratio of low and high sex ratio phenotypes varied in space and time. We adjusted the observed distribution of sex ratio phenotypes in each year $\times$ region combination to the sum of two binomial distributions, using a maximum-likelihood function. We assume that there are two possible average proportions of gynoparae in the offspring, $p_{1}$ and $p_{2}$, and that $\alpha$ is the proportion of individuals from the $p_{1}$ distribution and $1-\alpha$ is the proportion from the $p_{2}$ distribution. The probability of having $X$ gynoparae among $Y$ offspring is:

$$
\begin{aligned}
P(X)= & \alpha \frac{Y !}{X !(Y-X !)} p_{1}^{X}\left(1-p_{1}\right)^{Y-X} \\
& +(1-\alpha) \frac{Y !}{X !(Y-X) !} p_{2}^{X}\left(1-p_{2}\right)^{Y-X}
\end{aligned}
$$

For each site $\times$ ycar $\times$ region combination, we searched the parameters $p_{1}, p_{2}$ and $\alpha$ that maximized the function $\Sigma \ln (P(X))$. This was done using the Solver function of EXCEL 5.0. Observed and estimated distributions are presented in Fig. 2. Occasional irregularities of the estimated curves (e.g. at Colmar in 1993) resulted from the pooling of individual sex ratios into classes based on intervals of $10 \%$.

The fit between the model's predictions and the observed data was good; $\chi^{2}$-tests showed no statistical differences between predicted and observed distributions, except for Colmar in 1993. A consistently bimodal distribution of brood sex ratios was observed across years and regions. The two estimated modes varied little among years and regions (between 0.23 and 0.38 for the lower mode, between 0.86 and 0.98 for the upper mode), while the estimated proportions of each phenotype were more variable (Table 2). The lower mode (male-biased sex ratio) included the majority of individuals in all cases except at Colmar in 1992, where the estimated proportion of gynopara-biased producers was $54 \%$. The two regions differed in 1992, but were simitar in 1993 and 1994. Although a very small number (2) of gynoparac producers were observed at Rennes in 1991, this estimate might have been biased by small sample size (33 individuals from 11 clones). Because of the bimodality of sex ratio distribution, population sex ratio was estimated using the function $\alpha p_{1}+(1-\alpha) p_{2}$ instead of using the mean sex ratio of all parents. Though showing variation (Table 2), population sex ratios were rather close to the Fisherian equilibrium of 0.50 : only at Colmar, in 1992, was the estimated population sex ratio $(0.70)$ significantly different from 0.50 (goodness-of-fit test, $P<0.001)$ 

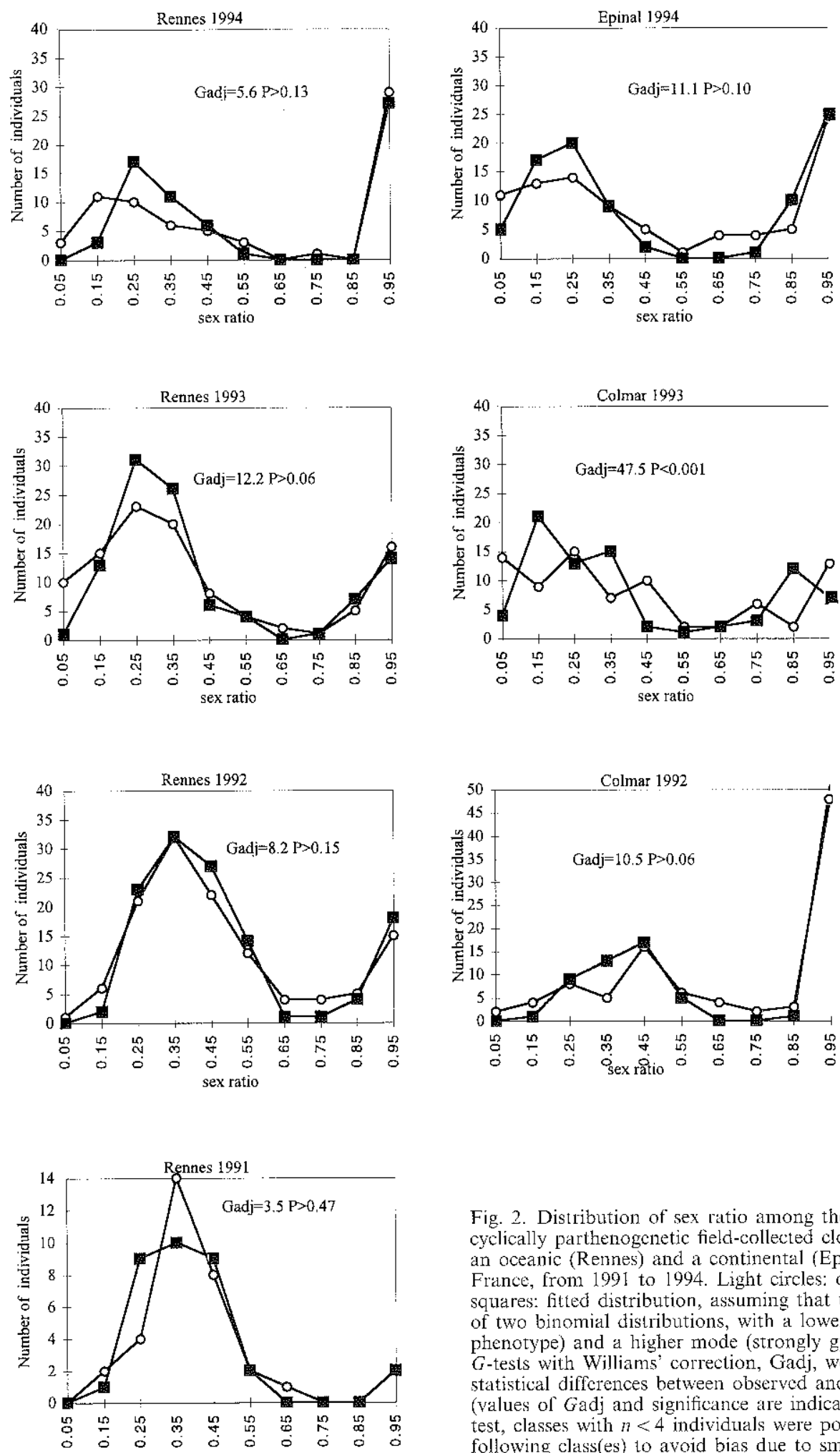

Fig. 2. Distribution of sex ratio among the pooled replicates of cyclically parthenogenetic field-collected clones of Rhopalosiphum padi, in an oceanic (Rennes) and a continental (Epinal and Colmar) region of France, from 1991 to 1994 . Light circles: observed distribution. Dark squares: fitted distribution, assuming that the real distribution is the sum of two binomial distributions, with a lower mode (male-biased phenotype) and a higher mode (strongly gynoparae-biascd phenotype) $G$-tests with Williams' correction, Gadj, were performed to test statistical differences between observed and predicted distributions (values of Gadj and significance are indicated on each figure). For this test, classes with $n<4$ individuals were pooled with the adjacent following class(es) to avoid bias due to small sample size. 
Table 2. Fstimated parameters of the distribution of individual sex ratios in cyclically parthenogenetic clones of Rhopalosiphum padi, under the assumption that the distribution is the sum of two binomial distributions. $N$, number of individuals, $p_{1}$, lower mode, $p_{2}$, upper mode, $\alpha$, proportions of individuals of the $p_{1}$ distribution, SR, estimated population sex ratio. $G$-tests indicato the significance of deviations of SR from 0.50 (ns, not significant; $* * P<0.001$ ).

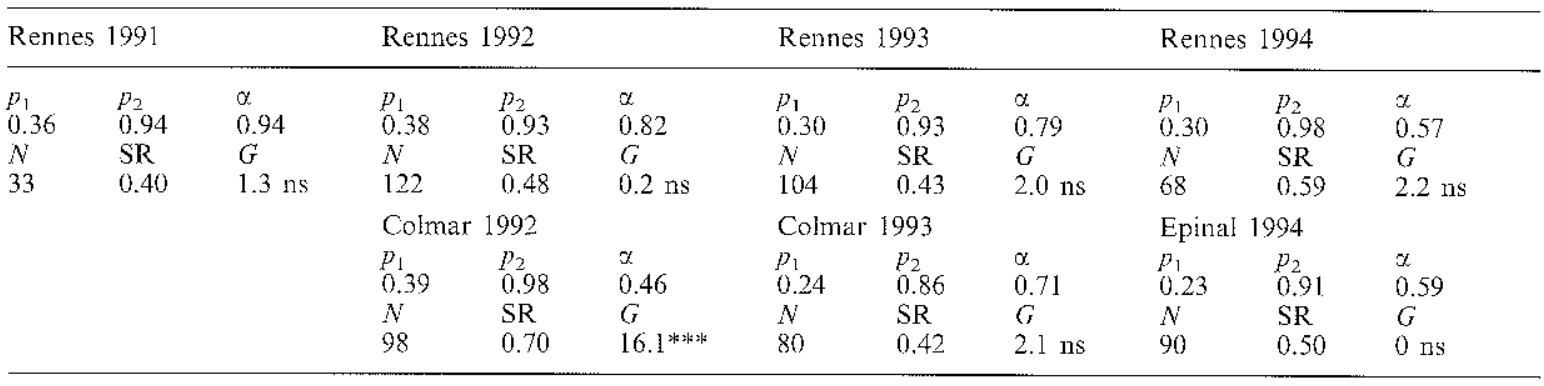

Sex ratio variability among clones

A substantial fraction of the clones consistently exhibitcd highly gynopara-biased sex ratio. Indeed, 30 clones produced a minimum of $90 \%$ gynoparae, of which 13 produced only gynoparae. The majority of the remaining clones had a sex ratio varying between 0 and $60 \%$ gynoparae (and a gynopara-biased mean sex ratio), while a third type of clone displayed more variation, including both highly gynopara-biased and male-biased sex ratios. In 16 clones, both sex ratios greater than $90 \%$ and less than $50 \%$ were recorded. Within that group, sex ratio did not correlate significantly with fecundity $(\rho=0.11, F=0.54, P=0.47)$ - contrasting with the significant correlation in the whole group of clones - but was strongly negatively correlated with longevity $(\rho=-0.40, F=8.95, P=0.004)$. Thus, in these clones, the high sex ratios might have been the artifactual result of decreased longevity of somc parents.

Confirmation of the existence of consistently male-biased and gynopara-biased clones

Experiment 1 suggested the existence of three types of clones, some consistently male-biased sex ratios, some with consistently gynopara-biased sex ratio, and some with rather variable sex ratios. But only three individuals were studied per clone, which likely led to underestimate intraclonal sex ratio variability. However, analyzing the brood sex ratios of 20 individuals per clone in experiment 2 conlirmed the existence of clones that were consistently male-biased (Colmar 10) and gynopara-biased (Colmar 15 and Rennes 18, Fig. 3). $G$-tests were used to assess the intraclonal sex ratio variation among the 20 replicates in experiment 2 and to test the deviation of the sex ratios from the mean sex ratio recorded in experiment 1 (with three replicates). Neither Colmar $10 \quad\left(G_{\text {beterogencity }}=21.3, \quad P>0.26\right.$; $\left.G_{\text {pooled }}=0.34, P>0.55\right)$ nor Rennes $18,\left(G_{\text {haterogencity }}=\right.$ $13.5, P>0.76 ; \mathrm{G}_{\text {pooled }}=0.03, P>0.86$ ) showed signifcant intraclonal heterogeneity or deviation from the mean sex ratio recorded in experiment 1 . One clone,
Colmar $15\left(G_{\text {helerogeneity }}=12.7, P>0.85 ; G_{\text {pooled }}=47.4\right.$, $P<0.001$ ), showed no significant heterogeneity but a slight, significant change in sex ratio between the two experiments, from 0.97 to 0.92 , on average.

Finally, in one clone that was very variable in experiment 1 (Colmar 1), the majority of broods were malebiased, while only one was strongly gynopara-biased (Fig. 3). It was produced by a female that had reduced fecundity and longevity as compared to the other replicates. However, the heterogeneity in sex ratio of the clone appeared to be only weakly significant while the change in sex ratio, from an average of 0.73 to 0.48 , was very significant $\left(G_{\text {heterogencity }}=30.8, \quad P=0.042\right.$; $G_{\text {pooled }}=978.6, P<0.0001$ ).

\section{Preliminary study of the inheritance of sex ratio differences}

Both parental clones, $\mathrm{F}$ and $\mathrm{H}$, showed male-biased sex ratios (Table 3), while no significant intraclonal variability was detected. In experiment 3 , twelve out of thirteen $\mathrm{F} \times \mathrm{F}$ clones showed also a significant malebias, while the remaining clone $\mathrm{F} \times \mathrm{F} 13$, showed no bias (Table 4). Eleven out of fourteen $\mathrm{H} \times \mathrm{H}$ clones showed a male bias, two were not significantly biased $(\mathrm{H} \times \mathrm{H} 22$ and $\mathrm{H} \times \mathrm{H} 29)$, while one was gynoparabiased $(\mathrm{H} \times \mathrm{H} 13)$. In the latter case and in clone $\mathrm{H} \times$ $\mathrm{H} 29$, the higher proportion of gynoparae (means 0.74 and 0.58 , respectively) was clearly correlated with a sharp decrease in fecundity compared to the other self-crosses. Finally, in the majority of the self-crossed clones (except four $\mathrm{F} \times \mathrm{F}$ and four $\mathrm{H} \times \mathrm{H}$ clones), no significant intraclonal variability was detected.

\section{Discussion}

\section{Evidence of bi-directional gene flow between cyclical and obligate parthenogens}

In western (oceanic) France, in 1991 and 1994, a substantial proportion of sexually produced clones were 
obligate parthenogens. Obligate parthenogens were observed too frequently to be explained by recurrent mutations causing an inability to produce gynoparae and a simultaneous transition from cyclical to obligate parthenogensis. Two other hypotheses may be advanced to explain the occurrence of obligately parthenogenetic clones. The first is that they originate from matings between males produced by obligate parthenogens and sexual females. The second hypothesis is that both parents were produced by cyclical parthenogens polymorphic for genes controlling life cycle. If the latter hypothesis is true, significant gene flow between life-cycles must be mediated by males from obligate parthenogens; otherwise, alleles for obligate parthenogensis would rapidly decrease in frequency and be lost in cyclical parthenogens. Because an appreciable proportion of sexually produced clones are obligate parthenogens, matings between males from obligate parthenogens and sexual, cyclically parthenogenetic females must have occurred in the evolutionarily recent past.

The occurrence of such matings is an important conclusion since it shows that gene flow between sexuals and asexuals is not unidirectional. Instead, obligate asexuals still contribute to the gene pool of sexual (cyclically parthenogenetic) lineages. To our knowledge, this direct evidence is a novel finding for aphids and confirms previous indirect evidence for gene flow obtained with molecular markers (Martinez-Torres et al. 1996, Simon et al. 1996a). A study of regional variation in mtDNA haplotypes (Martinez-Torres et al. 1997) showed that the proportion of obligate parthenogens with haplotype II, typical from cyclical parthenogens, increased along a warm to cold climatic gradient. This pattern suggests that obligately parthenogenetic lineages are more commonly produced by sexual reproduction in the most northerly locations. Consistent with this idea, a study from Simon et al. (1996b) showed that obligate parthenogens dominate in the milder regions of France (west and south), while cyclical parthenogens dominate in the colder northeastern, and both types co-occur in the north. Thus, gene flow between cyclical and obligate parthenogens is likely to be highest in the northern regions. In contrast, the present study revealed production of obligately parthenogenetic lineages in the mildest region (Rennes), rather than in the coldest one (Colmar and Epinal). The number of clones studied might, however, have been too small to demonstrate statistical differences between the two regions. More extensive sampling and the use of life-cycle-associated molecular markers are needed to accurately estimate the level of gene flow between cyclical and obligate parthenogens.
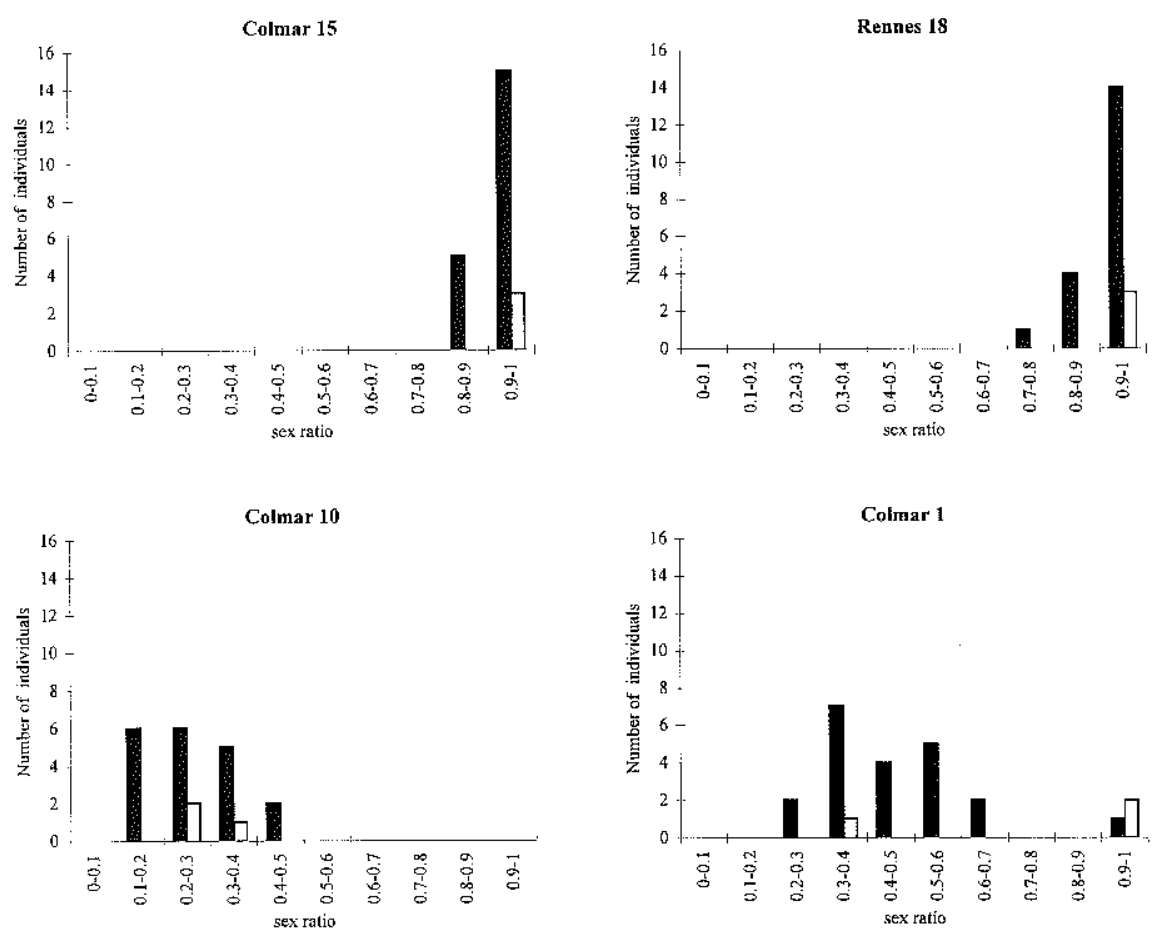

Fig. 3. Test of the consistency of sex ratio biases among four cyclically parthenogenetic field-collected clones of Rhopalosiphum padi. Light, distribution of sex ratio phenotypes among three replicates in experiment 1 . Dark, distribution of sex ratio phenotypes among twenty replicates in experiment 2 
Table 3. Responses of two clones of Rhopalosiphum padi, $\mathrm{F}$ and $\mathrm{H}$, to conditions inducing the production of sexuals $\left(12 \pm 1^{\circ} \mathrm{C}\right.$, L:D 10:16). Number of parents tested $(n)$ and clonal mean numbers of gynoparae and males (S.D. within parentheses) and sex ratio, calculated as proportion of gynoparae. Intraclonal heterogeneity for sex ratio and deviation of the sex ratios from 0.50 were tested using $G$-tests for goodness of fit, with respectively $G_{\text {heterogencily }}$ and $G_{\text {pooled }}$ Ns, not significant; $* * P<0.01$; $* * * P<0.001$. These clones were ultimately self-crossed.

\begin{tabular}{|c|c|c|c|c|c|c|}
\hline Clone & $n$ & Gynoparae & Males & Sex ratio & $G_{\text {lueterogeneity }}$ & $G_{\text {pooled }}$ \\
\hline $\mathrm{F}$ & 10 & $\begin{array}{r}9.0 \\
(4.2)\end{array}$ & $\begin{array}{l}17.1 \\
(7.6)\end{array}$ & 0.34 & $13.1 \mathrm{~ns}$ & $25.6^{* * *}$ \\
\hline $\mathrm{H}$ & 9 & $\begin{array}{r}8.0 \\
(3.7)\end{array}$ & $\begin{array}{l}12.3 \\
(5.6)\end{array}$ & 0.39 & $3.8 \mathrm{~ns}$ & $8.4^{* * *}$ \\
\hline
\end{tabular}

\section{Sex ratio variation}

We have revealed two sex ratio phenotypes in $R$. padi under laboratory conditions. One is male-biased ( $\sim 30 \%$ gynoparae), the other strongly gynopara-biased ( 95\% gynoparae). Several difficulties arise, however, when trying to determine whether this pattern is due to genetically based differences among clones. First, clones could show variable responses under progressively declining photoperiod and temperatures as encountered in the field. If, for example, more males are produced in the late fall, the sex ratio of a clone in naturc may differ from that observed under laboratory induction experiments. However, our observation of extreme sex allocation differences among clones under identical inducing conditions indicates some degree of genetic control. It could be that clones simply vary in their threshold responses to temperature/photoperiod. Under this hypothesis, all clones could show similar although temporally displaced distributions of sex allocation over time, as suggested by Austin et al. (1996) who showed that some clones of $R$. padi display sequential patterns of allocation under a decreasing photoperiod. Contradicting this are results from an experiment using laboratory-simulated naturally decreasing day length and tcmperature, which showed that two 'gynoparae-producing' clones yielded a lifetime total of $>95 \%$ gynoparae while two "male-producing" clones yielded mostly males (Hullé et al. 1999).

Another difficulty in comparing clones arises from the limited number of replicates for assessing withinclone variation in sex allocation. For example, only three were used in the first experiment, on ficld-collected clones. In this study, extensive variation was observed among replicates from several clones, and clones showing a homogeneous response (with replicates all male- or gynopara-biased) may have the capacity for more variation. However, other data, such as that from experiment 2 , demonstrate that some clones are consistently male- or gynopara-biased, suggesting a genetic basis for sex allocation. Additionally, most clones from the two self-crosses $\mathrm{F} \times \mathrm{F}$ and $\mathrm{H} \times \mathrm{H}$ ) yielded offspring that produced homogeneously malebiased sex ratios. That the parental $(F, H)$ clones were also male-biased further supports a heritable genetic basis for sex allocation traits.
One remaining difficulty is the relatively high intraclonal variation observed in some clones. One clone yielded both male- and gynopara-biased sex ratios among three replicates in the first experiment but yielded mostly homogeneously male-biased sex ratios among 20 replicates in experiment 2 . The only replicate with a strongly gynopara-biased sex ratio had a reduced life-span and fecundity. Similarly, in the first experiment, the study of the most variable clones showed that high sex ratios within that group arose from short-lived individuals. In the two latter cases, gynopara-biased sex ratios may be artifactual. Further studies will be necessary to assess the extent of sex ratio variation within clones.

\section{Possible adaptive significance of sex ratio polymorphism in $R$. padi}

The phenomenon of coexistence of clones specializing in female production with clones that produce both sexes is analogous to gynodioecy in plants (the coexistence of female plants with hermaphrodites). While evidence of gynodioecy in animals is scarce (Ghiselin 1969), Innes and Dunbrack (1993) have shown a pattern of sex allocation in cladocerans (Daphnia) that is strikingly similar to the pattern we have observed in aphids: in both cases, clones produce either only females or mostly males. Theoretical models on the stability of gynodioecious mating systems, show that the maintenance of females would be ensured if they are more than twice as fecund as hermaphrodites (Lloyd 1974, Charlesworth and Charlesworth 1978). This could happen either if hermaphrodites suffer from reduced fecundity caused by inbreeding depression, or if females compensate the loss of the male function by an increased ovule production. Our observations on $R$. padi suggest that both conditions (or equivalent conditions) could be met.

First, the decrease in fecundity from parental to self-crossed clones (from 20.3 larvae in clone $\mathrm{F}$ to 14.1 in $\mathrm{F} \times \mathrm{F}$ clones $(t=2.85, P(T \leq t) \leq 0.0 \mathrm{l})$, from 26.1 in clone $\mathrm{H}$ to 18.8 in $\mathrm{H} \times \mathrm{H}$ clones $(t=2.87, P(T \leq t)<$ $0.01)$ ) might indicatc a cost of inbreeding, as has been demonstrated in the aphid Sitobion avenae (New- 
ton and Dixon 1988, Helden and Dixon 1997, Dedryver et al. 1998). Still, the likelihood of inbreeding in the field may be very small, because gynoparae and males of $R$. padi disperse, flying to a non-natal host (Ward and Wellings 1994). The risk of inbreeding may be increased if any of several factors hold: (a) dispersal distances are small for most individuals, (b) the winterhost is rare locally, or (c) summer competition between clones is so intense that few clones remain to produce sexuals in the fall (Simon et al. 1991).

Second, the fecundity of parents with highly gynopara-biased sex ratios is higher than that of parents with male-biased sex ratios by a factor $1.4: 1$. This fitness advantage might, however, be insufficient to account by itself for the maintenance of the two alternative phenotypes, which could result both from the cost of inbreeding and from the increased fecundity of the highly gynopara-biased parents. However, most of the gynopara-biased clones produce a low quantity of males, so the mating system of $R$. padi does not seem to be strictly gynodioecious.

\section{Expected population sex ratios}

Populational sex ratios were estimated based on the distribution of sex allocation phenotypes. Our laboratory studies suggest that they remain close to the Fisherian equilibrium 1:1. In $R$. padi, males and gynoparae are produced on the summer-host; they fly independently to the winter host where sexuals mate. Therefore, panmixis and Fisherian equilibrium are actually expected to occur (Moran 1993). This observation is not in contradiction with the interpretation of biased sex ratios as a way to diminish the risk of inbreeding, since even rare instances of inbreeding may constitute a selective pressure for the maintcnance of biased sex ratios (Innes and Dunbrack, 1993). This situation contrasts with the case of other aphid species in which the sexuals do not host-alternate (Yamaguchi 1985, Foster and Benton 1992) and in which female-biased sex ratios have been observed and linked with "local mate competition" (Hamilton 1967).

Extrapolating these sex ratios to those found in nature is difficult, however, since under optimal laboratory conditions of induction, all reproductive sequences wcre completed. In the field, higher mortality would likely bias the sex ratio further towards gynoparae, which are produced before males (Dixon and Glen 1971). Indeed, data from the collection of autumnflying $R$. padi showed that gynoparae may largely outnumber males in regions where the climate is cold and the population presumably mostly made of cyclical parthenogens (Rispe et al. 1998a). Estimating population sex ratio in the field may be even more complex if obligate parthenogcns produce a substantial proportion of males. Because these males have been shown to occasionally mate with sexual females, they must be

Table 4. Mean sex ratio and fecundity of clones of Rhopclosiphum padi from two laboratory sell-crosses $\mathrm{F} \times \mathrm{F}$, and $\mathrm{H} \times \mathrm{H}(n$ : number of parents tested). Intraclonal heterogeneity for sex ratio and deviation of the sex ratios from 0.50 were tested using $G$-test for goodness of fit, with respectively $G_{\text {leiccrogerncity }}$ and $G_{\text {paoled }}$. No sign, not significant; $* *<0.05 ; * * P<0.01 ; * * * P<0.001$

\begin{tabular}{|c|c|c|c|c|c|}
\hline Clone & $n$ & Sex ratio & Fecundity & $G_{\text {heterogeneity }}$ & $G_{\mathrm{y} p o o l e d}$ \\
\hline $\mathrm{F} \times \mathrm{F} 2$ & 12 & 0.38 & 17.3 & 5.1 & $13.7 * * *$ \\
\hline $\mathrm{F} \times \mathrm{F}_{3}$ & 17 & 0.34 & 17.4 & $30.9^{*}$ & $40.3^{* * * *}$ \\
\hline$F \times F 4$ & 17 & 0.31 & 16.4 & 17.7 & $41.5^{\text {**** }}$ \\
\hline$F \times F 5$ & 15 & 0.28 & 17.9 & $27.8^{*}$ & $56.4^{* * * *}$ \\
\hline $\mathrm{F} \times \mathrm{F} 8$ & 8 & 0.20 & 17.5 & 5.3 & $54.0^{0 * * * *}$ \\
\hline $\mathrm{F} \times \mathrm{F} 11$ & 13 & 0.28 & 25.4 & 6.2 & $62.5^{* * ;: k}$ \\
\hline $\mathrm{F} \times \mathrm{Fl2}$ & 16 & 0.35 & 15.4 & 19.7 & $21.9^{* * * *}$ \\
\hline $\mathrm{F} \times \mathrm{F} 13$ & 13 & 0.50 & 18.8 & $29.1 * *$ & 0.6 \\
\hline$F \times F 15$ & 16 & 0.41 & 17.0 & $52.2 * * *$ & $16.2 \% * *$ \\
\hline $\mathrm{F} \times \mathrm{F} 21$ & 14 & 0.43 & 21.4 & 15.3 & $10.2 * * * *$ \\
\hline $\mathrm{F} \times \mathrm{F} 29$ & 13 & 0.22 & 15.5 & 10.1 & $63.3 * * *$ \\
\hline$F \times F 31$ & 10 & 0.28 & 23.1 & 14.4 & $43.8 * * *$ \\
\hline $\mathrm{F} \times \mathrm{F} 32$ & 10 & 0.35 & 20.9 & 6.4 & $23.2^{* * * * *}$ \\
\hline $\mathrm{H} \times \mathbf{H} 2$ & 17 & 0.19 & 20.6 & 14.0 & 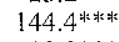 \\
\hline $\mathrm{H} \times \mathrm{H} 3$ & 8 & 0.36 & 12.3 & 10.7 & $12.0^{* * * * *}$ \\
\hline $\mathrm{H} \times \mathrm{H} 4$ & 14 & 0.38 & 12.9 & 19.9 & $10.9^{* * *}$ \\
\hline $\mathrm{H} \times \mathrm{H}_{6}$ & 17 & 0.40 & 13.3 & 24.0 & $13.0 \%$ \\
\hline $\mathrm{H} \times \mathrm{H} 8$ & 17 & 0.38 & 16.0 & $33.6^{* *}$ & $34.6 * \% *$ \\
\hline $\mathrm{H} \times \mathrm{H} 10$ & 8 & 0.35 & 16.3 & $17.3^{*}$ & $15.2 \%$ *k \\
\hline $\mathrm{H} \times \mathrm{H} 13$ & 8 & 0.74 & 9.5 & 4.0 & 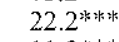 \\
\hline $\mathrm{H} \times \mathrm{H} 18$ & 17 & 0.42 & 14.2 & $42.5^{\text {***** }}$ & $11.3^{* * * *}$ \\
\hline $\mathrm{H} \times \mathrm{H} 19$ & 12 & 0.36 & 13.3 & 15.7 & $20.0^{* * * * *}$ \\
\hline $\mathrm{H} \times \mathrm{H} 21$ & 11 & 0.33 & 13.7 & 6.6 & $19.0^{\text {***** }}$ \\
\hline $\mathrm{H} \times \mathrm{H}_{22}$ & 13 & 0.46 & 12.8 & 13.4 & $1.3 * * *$ \\
\hline $\mathrm{H} \times \mathrm{H} 26$ & 19 & 0.32 & 13.2 & 23.0 & $41.3^{* * *}$ \\
\hline $\mathrm{H} \times \mathrm{H} 29$ & 19 & 0.58 & 9.3 & $32.7^{*}$ & $3.0^{* * * *}$ \\
\hline $\mathrm{H} \times \mathrm{H} 33$ & 11 & 0.27 & 15.0 & 6.2 & $41.5^{* * * * *}$ \\
\hline
\end{tabular}


taken into account when determining the population sex ratio. Furthermore, cyclical parthenogens should produce extra gynoparae to balance these exogenous males. This hypothesis could be tested by sampling individuals dispersing to $P$. padus in the fall, determining relative numbers of gynoparae versus males, and using molecular markers (Simon et al. 1996a) to infer the proportion of males produced by cyclical and obligate parthenogens.

Acknowledgements Thanks to Jacques Mallard, Nancy Moran, Manuel Plantegenest, Donald Miller and Paul Sunnucks for their comments and suggestions, and to Dan Funk, for his extensive comments on the paper. This work was supported by a grant from the French Ministère de l'Agriculture.

\section{References}

Austin, A. B. M., Tatchell, G. M., Harrington, R. and Bale, J. S. 1996. Adaptive significance of changes in morph production during the transition from the parthenogenetic to sexual reproduction in the aphid Rhopalosiphim padi (Homoptera: Aphididac). - Bull. Entomol. Res. 86: 93-99.

Blackman, R. L. 1972. The inheritance of life-cycle differences in Myzus persicae (Sulz.) (Hem., Aphididae). - Bull. Entomol. Res. 62: 281-294.

Blackman, R. L. 1974. Life-cycle variation of Myzus persicae (Sulz.) (Hom., Aphididae) in different parts of the world, in relation to genotype and environment. - Bull. Entomol Res. 63: $595 \% 607$.

Charlesworth, B. and Charlesworth, D. 1978. A model for the evolution of dioecy and gynodioecy. - Am. Nat. 112: 975-997

Charnov, E. L. 1982. The theory of sex allocation. - Princeton Univ. Press, Princeton, N.J.

Crema, R. 1979. Egg viability and sex determination in Megoura viciae (Homoptera, Aphididac). - Entomol. Exp. Appl. 26: 152-156.

Dean, G. J. 1974. The overwintering and abundance of cereal aphids. - Ann. App1. Biol. 76: 1-7.

Dedryver, C. A. and Gellé. A. 1982. Biologie des pucerons des céréales dans l'ouest de la France. IV-Etude de l'hivernation des populations anholocycliques de Rhopalosiphum padi L., Metopolophium dirhodum W1k et Sitobion atenate F. sur repousses de céréales dans trois stations de Bretagne et du Bassin parisien. - Acta Oecol. Oecol. Appl. 3: $321-342$.

Dedryver, C.-A., Le Gallic, J.-F., Gauthier, J. P. and Simon, J. C. 1998. Life cycle of the cereal aphid Sitobion avenae F polymorphism and comparison of life history traits associated with sexuality. - F.col. Entomol. 23: 123132.

Dixon, A. F. G. and Glen, D. M. 1971. Morph determination in the bird cherry-oat aphid Rhopalosiphum padi L. '.. Ann. Appl. Biol. 68: 11-21.

Fisher, R. A. 1930. The genetical theory of natural selection. Oxford Univ. Press, Oxford.

Foster, W. A. and Benton, T. G. 1992. Sex ratio local mate competition and mating behaviour in the aphid $P_{\text {emphigh }}$ spirothecae. - Behay. Ecol. Sociobiol. 30: 297. 307.

Ghisclin, M. T. 1969. The evolution of hermaphroditism among animals. - Q. Rev. Biol. 44: 189--208.

Godfray, I. C. J. 1990. The causes and consequences of constrained sex allocation in haplodiploid animals. - J. Evol. Biol. 3: 3-17.

Hamilton, W. D. 1967. Extraordinary sex ratios. - Scienco I 56: $477-488$.
Hamilton. W. D. 1980. Sex versus non-sex versus parasite. Oikos 35: 282-290.

Hebert, P. D. N. 1981. Obligate asexuality in Daphnia. - Am. Nat. 117: $784-789$

Hebert, P. D. N., Beaton, M. J, Schwartz, S. S. and Stanton, D. J. 1989. Polyphyletic origins of asexuality in Daphnia pulex. I. Breeding-system variation and levels of clonal diversity. - Evolution 43: 1004-1015.

Helden, A. J. and Dixon, A. F. G. 1997. Inbreeding and egg hatching in Sitobion avenae. ... Ecol. Entomol. 22: 124-126.

Hille Ris Lambers, D. 1966. Polymorphism in Aphididae. Annu. Rev. Entomol, 11: 47-78.

Hullé, M., Maurice, D., Rispe, C. and Simon, J.-C. 1999 Clonal variability in sequences of morph production during the transition from parthenogenetic to sexual reproduction in the aphid Rhopalosiphum padi (Homoptera: Aphididae). Eur. J. Entomol. (in press).

Hurst, L. D. and Peck, J. R. 1996. Recent advances in understanding of the evolution and maintenance of sex. Trends Ecol. Evol. 11: 46-52.

Innes, D. J. and Dunbrack, R. L. 1993. Sex allocation variation in Daphnia pulex. J. Evol. Biol. 6: 559-575.

Innes, D. J. and Hebert, P. D. N 1988. The origin and genetic basis of obligate parthenogenesis in Duphnia pulex. Evolution 42: 1024-1035.

Lampel, G. 1968. Die Biologie des Blattlaus-generationswechscls. - Gustay Fischer. Jcna.

Lees, A. D. 1966. The control of polymorphism in aphids. Adv. Inscet Physiol. 3: 207-277

Lloyd. D. G. 1974. The genetic contributions of individual males and females in dioecious and gynodioecious angiosperms. - Heredity 32: 45-51.

Lynch, M. and Gabriel, W. 1983. Phenotypic evolution and parthenogenesis. ... Am. Nat. 122: 745764

Martinez-Torres, D., Simon, J. C., Ferreres, A. and Moya, A. 1996. Genetic variation in natural populations of the aphid Rhopalosiphum padi as revealed by maternally inheritcd markers. - Mol. Ecol. 5: 659-670.

Martinez-Torres, D., Moya, A., Hebert, P. D. N. and Simon, J.-C. 1997. Grographic distribution and seasonal variation of mitochondrial DNA haplotypes in the aphid Rhopalosiphum padi (Hemiptera: Aphididae). - Bull. Entomol. Res. 87: $161-167$.

Maynard Smith, J. 1971. What use is sex? - J. Theor. Biol, 30: 319-335.

Michod, R. E. and Levin, B. R. 1988. The evolution of sex: an examination of current ideas. -. Sinauer, Sunderland, MA.

Moran, N. A. 1992. The evolution of aphid life-cycles. Annu. Rev. Entomol. 37: 321-348.

Moran, N. A. 1993. Evolution of sex ratio variation in aphids. In: Wrensch, D. L. and Ebbert, M. A. (eds), Evolution and diversity of sex ratio in insects and mites. Chapman \& Hall, pp. $346-368$.

Newton, C. and Dixon, A. F. G. 1987. Cost of sex in aphids: size of males at birth and the primary sex ratio in Sitobion atenae (F.). - Funct. Ecol. 1: 321-326

Newton, C. and Dixon, A. F. G. 1988. A preliminary study of variation and inheritance of life-history traits and the occurrence of hybrid vigour in Sitobion avenae (F.) (Heniptera: Aphididae). - Bull. Entomol. Res. 78: 75-83.

Remaudière, G. 1953. Nutrition et variations du cycle évolutif des Aphidoidea. - Rev. Pathol. Veg. Entomol. Agric. Fr. 32: $190-207$.

Rispe, C., Hullé, M., Gauthier, J. P., Pierre, J. S, and Harrington, R. 1998a. Effect of climate on the proportion of males in the autumn flight of the aphid Rhopalosiphum padi $\mathrm{L}$. J. Appl. Entomol. 122: 129-136.

Rispe, C., Pierre, J.-S., Simon, J.-C. and Gouyon, P.-H. 1998 b. Models of sexual and ascxual coexistence in aphids based on constraints. - J. Evol. Biol. 11:685-70 I.

Simon, J.-C., Blackman, R. L. and Le Gallic, J.-F. 1991. Local variability in the life-cycle of the bird cherry-oat Rhopalosiphum padi (L.) in westem France. - Bull. Entomol. Res. $81: 315-322$. 
Simon, J.-C., Le Gallic, J.-F., Bonhomme, J. and Dedryver C.-A. 1994. Breeding system complex in the cereal aphid Rhopalosiphum padi (Homoptera: Aphididae) and its influences on population biology and dynamies. - Bull. OILB SROP 17: 11-15.

Simon, J.-C., Martinez-Torres, D., Latorre, A., Moya, A. and Hebert, P D. N. 1996a. Molecular characterization of cyclic and obligate parthenogens in the aphid Rhopalosiphum padi (L.). - Proc. R. Soc. Lond. B 263: 481-486.

Simon, J.-C., Carrel, E., Hebert. P. D. N., Dedryver, C.-A. Bonhomme, J. and Le Gallic, J. F. 1996b. Genetic diversity and mode of reproduction in French populations of the aphid Rhopalosiphum padi L. - Heredity 76: 305-313.

Stearns, S. C. 1990. The evolutionary maintenance of sexual reproduction: the solution proposed for a longstanding problem. - J. Genet. 69: 1 -10.

Tatchell, G. M., Plumb, R. T. and Carter, N. 1988. Migration of alate morphs of the bird cherry aphid (Rhopalosiphum padi) and implications for the epidemiology of the barley yellow dwarf virus. - Ann. Appl. Biol. 112: 1-11.

Ward, S. A and Wellings, P. 1994 . Deadlines and delays as factors in aphid sex allocation. Eur. J. Entomol. 91: $29-36$.

Williams, G. C. and Mitton, J. B. 1973. Why reproduce sexually? - J. Theor, Biol. 39: 545-554.

Williams, G. C. 1975. Sex and evolution. - Princeton Univ. Press, Princeton, NJ.

Wöhmmann, K, and Tomiuk, J. 1988. Life cycle strategies and genotypic variability in populations of aphids. - J. Genet. 67: $43-52$.

Yamaguchi, Y. 1985. Sex ratios of an aphid subject to local mate competition with variable maternal condition. - Nature 318: 460-- 462 .

\section{Appendix}

Schematic diagram of the life-cycle of the aphid Rhopalosiphum padi from late summer to spring (covering the sexual phase of the cyclical parthenogens) and analytical proof of the expectation of an equal investment between gynoparae and males. Dashed lines indicate several parthenogenetic generations of overwintering asexuals.

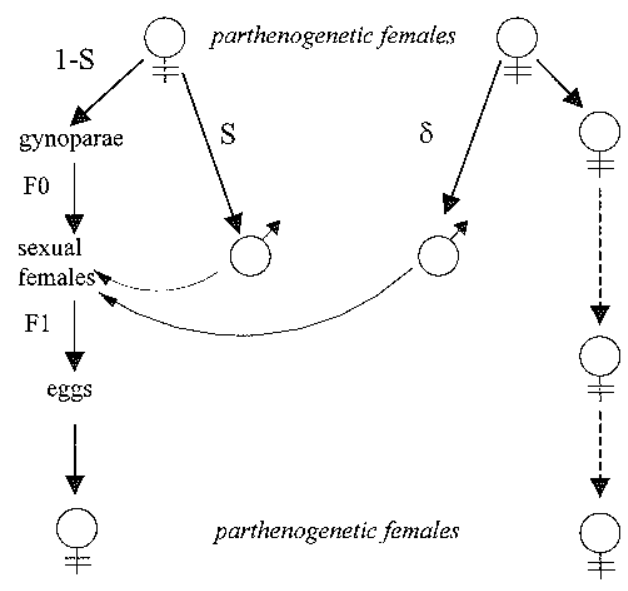

A gynopara gives birth to $F 0$ sexual females, which in turn lay $F 1$ eggs after mating. 1) In a population purely made of cyclical parthenogens, the fitness of a parthenogenctic female producing $1-S$ gynoparae and $S$ males after induction, as measured in number of eggs is: $W=(1-S) F 0 F 1+S(N F / N M) F 1$ where $N F / N M$ is the average ratio between the numbers of sexual females and males. The ESS investment ratio must check $(\hat{O} W / \partial S)=0$ which comes to $(N F / N M)-F 0=0$. At equilibrium, we may write that $(N F / N M)=F 0(1-$ $\left.S^{*}\right) / S^{*}$ so the investment in gynoparae should be $S^{*}=$ $\frac{1}{2}$, while there should a $F 0: 1$ ratio between sexual females and males. 2) If obligate parthenogens also produce some males (adding a quantity $\delta$ of males to the pool of sexuals $)$ we have $(N F / N M)=\left(F 0\left(1-S^{*}\right)\right.$ $\left.S^{*}+\delta\right)$ So, at equilibrium, $S^{*}=(1-\delta / 2)<\frac{1}{2}$. Maleproduction by obligate parthenogens should cause a bias towards gynoparae in cyclical parthenogens. 